\title{
The Impact of Perceived Social Support on Anxiety, Depression and Severity of Pain and Burnout Among Turkish Females With Fibromyalgia
}

\author{
Nermin GÜNDÜZ(1) ${ }^{1}$, Ahmet ÜŞEN (1) ${ }^{2}$, Emel AYDIN ATAR (1) 3 \\ ${ }^{1}$ Department of Psychiatry, Dumlupinar University Faculty of Medicine, Kütahya, Turkey \\ ${ }^{2}$ Department of Physical Therapy and Rehabilitation, Bezmiâlem Vakıf University, İstanbul, Turkey \\ ${ }^{3}$ Department of Physical Therapy and Rehabilitation, İstanbul Sultan Abdulhamit Han Training and Research Hospital, İstanbul, Turkey
}

\begin{abstract}
Objectives: This study aims to assess the impact of perceived social support on burnout, severity of pain and comorbid anxiety and depression among Turkish females with fibromyalgia syndrome (FMS).

Patients and methods: A total of 117 females including 65 patients with FMS (mean age $33.5 \pm 8.1$ years; range 20 to 60 years) and 52 healthy controls (mean age 33.6 \pm 7.3 years; range 23 to 48 years) were included between January 2017 and May 2017. Following a semi-structured psychiatric interview by a psychiatrist, Sociodemographic Data Form, Mood and Anxiety Disorders Modules of Structured Clinical Interview for Diagnostic and Statistical Manual of Mental Disorders fourth edition Axis I Disorders (SCID-I), Hamilton Depression Rating Scale (HDRS), Hamilton Anxiety Rating Scale (HARS), visual analog scale (VAS), Maslach Burnout Inventory (MBI) and Multidimensional Scale of Perceived Social Support (MSPSS) were applied to participants.

Results: As a result of the semi-structured clinical interview conducted by a psychiatrist, the prevalence of any mood or anxiety disorder was found to be significantly more common in the FMS group. The proportion of patients diagnosed with any mood or anxiety disorder using SCID-I was significantly different among FMS $(n=50,76.92 \%)$ and healthy control $(n=14,33.33 \%)$ groups $(p<0.001)$. Correlations between these variables were examined within the FMS group. There was a significant negative correlation between VAS and MSPSS. There were significant negative correlations between MSPSS and HDRS, HARS, all subscales of MBI. There were significant positive correlations between VAS and HDRS, HARS, all subscales of MBI.

Conclusion: In conclusion, perceived social support was found to be strongly associated with depression, anxiety, burnout and severity of pain in patients with FMS. Our study provided support to emphasize the importance of perceived social support among females with FMS. Considering that FMS is associated with many physical and cognitive complaints in addition to pain, it can be considered as a multi-systemic disease requiring a multidisciplinary approach.

Keywords: Anxiety, burnout, depression, fibromyalgia syndrome, perceived social support.
\end{abstract}

Fibromyalgia syndrome (FMS) is a non-articular rheumatic disease characterized by chronic, widespread body pain in combination with excessive tenderness at specific anatomical sites. ${ }^{1}$ As a complex and difficult to treat condition, it is the most common cause of chronic musculoskeletal pain in females aged 20 to 55 years, with a prevalence of approximately $2 \% .^{2}$ In a study by Topbas et $\mathrm{al}^{3}{ }^{3}$ in Trabzon, the prevalence of FMS was 3.6\% among females aged between 20 and 64 and $0.9 \%$ among those between 20 and $29 .^{3}$

Fibromyalgia syndrome is not only more frequent among females, but also presents with a greater variety of signs and symptoms in

Received: May 07, 2018 Accepted: June 28, 2018 Published online: September 04, 2018

Correspondence: Nermin Gündüz, MD. Dumlupınar Üniversitesi Tıp Fakültesi Psikiyatri Anabilim Dalı, 43030 Kütahya, Turkey. Tel: +90 274 - 2652286 e-mail: ngunduz2798@hotmail.com 
females, compared to males. Complaints such as fatigue, sleep disturbances, impaired cognitive functions, anxiety and depression are frequently reported in these patients. So, the presence of these complaints must be carefully questioned in patients with FMS. ${ }^{4}$

The exact pathophysiology of FMS is still unknown and there are no definitive, measurable and visible indicators of disease activity. Unfortunately, this makes FMS an "invisible illness" that is difficult to recognize and be properly treated by clinicians. ${ }^{5}$ Invisible illness is described as "one that is hidden so as not to be immediately noticed by a clinician except under unusual conditions or by disclosure from the disabled individual or an external resource". 6 FMS is a complex disease to be coped with accompanying psychological distress associated with living with this invisible illness. Coping strategies for this complex illness are also important and specific for individuals. ${ }^{7}$ One of the most important coping methods for FMS is social support. Social support can be characterized as a proper coping resource diminishing the negative psychological effects of existing stressors and having important effects on the prognosis of chronic illnesses like FMS. ${ }^{8}$ An important point of view regarding social support is the alterations in the perception of social support through the severity of symptoms. Social support has also been conceptualized according to external resources demanded by individuals in need, and can be evaluated through the perceptions of individuals. ${ }^{9}$ that are generally obtained from family members, partners, relatives, friends and colleagues. ${ }^{10}$

Two types of social support subgroups have been put forward named as received social support and perceived social support. Received social support is the actual amount of support an individual receives when facing a stressor, while perceived social support is the individual's thought that the support is available if needed. Perceived social support is important, particularly when the support is coming from the same person through similar ways. ${ }^{11}$ We have considered the perceived social support in this study.

Research has revealed a strong relationship between social support and decreased risk for mental and physical diseases., ${ }^{9,12,13}$ Regardless of the type of chronic illness, positively perceived social support has resulted in positive treatment outcomes, including accompanying psychiatric illnesses. One of these chronic illnesses is FMS. ${ }^{13}$ Perceived social support from family, friends, and other members of one's social group for comfort and help with duties related to daily activities can be a great source of assistance; thus, social support is also important for a patient with FMS. ${ }^{13}$

We have noticed that there is a gap in the literature about the impact of perceived social support on the severity of pain, burnout and comorbid anxiety and depression among FMS patients. Therefore, in this study, we aimed to assess the impact of perceived social support on burnout, severity of pain and comorbid anxiety and depression among Turkish females with FMS.

\section{PATIENTS AND METHODS}

As FMS is more common in females, female subjects alone were included in this case-control study. The study included patients who met the American College of Rheumatology criteria for FMS $^{1}$ and was conducted between January 2017 and May 2017 at Physical Medicine and Rehabilitation (PMR) Department in Erzurum Regional Training and Research Hospital. Patients who were illiterate, had significant visual, hearing or cognitive impairment of communication, accompanied by inflammatory rheumatic disease or autoimmune disease, patients with mental retardation or psychotic disorder, those with steroid use, those with substance use, or those with chronic neurological disease with significant cognitive decline were excluded. Sixty-nine consecutive patients who applied to the outpatient clinic of PMR Department in Erzurum Training and Research Hospital were recruited for this study. Four patients with FMS refused to participate. Thus the sample group consisted of 117 females including 65 patients with FMS (mean age $33.5 \pm 8.1$ years; range 20 to 60 years) and 52 healthy controls (mean age 33.6 \pm 7.3 years; range 23 to 48 years). Necessary information concerning the questionnaires and the aim of the study were provided to the patients prior to the interview. Following a semi-structured psychiatric interview, the relevant scales were applied. The study was approved by Erzurum Training and Research Hospital Ethics Committee for Clinical 
Trials. A written informed consent was obtained from each participant. The study was conducted in accordance with the principles of the Declaration of Helsinki.

Sociodemographic Data Form: In this form, participants were asked about personal information such as age, marital status, educational status, working status, place of residence, smoking, additional physical illnesses and psychiatric history.

Structured Clinical Interview for Diagnostic and Statistical Manual of Mental Disorders fourth edition Axis I Disorders (SCID-I): This is a semi-structured clinical interview developed for use of mental health professionals. ${ }^{14}$ The SCID-I allows diagnosis of both present and lifetime Axis I mental disorders.

Hamilton Depression Rating Scale (HDRS): This 17-item scale questioning the depressive complaints in the past week is administered by the physician. The maximum score is 53 points. The scoring is as follows: 0-7 points indicates "no depression", 8-15 points indicates "mild depression", 16-28 points indicates "moderate depression", 29 points and above indicates "severe depression". ${ }^{15}$ The reliability and validity of the Turkish version are available. ${ }^{16}$

Hamilton Anxiety Rating Scale (HARS): This scale consists of 14 questions about both psychological and physical symptoms of anxiety. It determines the level of anxiety within the last 72 hours. It is evaluated as follows: $0-5$ points indicates "no anxiety"; 6-14 points indicates "minor anxiety"; 15 points and above indicates "major anxiety". ${ }^{17}$ The reliability and validity of the Turkish form are present. ${ }^{18}$

Maslach Burnout Inventory (MBI): The MBI was developed by Maslach and Jackson. ${ }^{19}$ The reliability and validity of the Turkish form were developed by Ergin and Çam. ${ }^{20}$ This 22-item inventory has three subscales: emotional exhaustion, depersonalization, personal accomplishment. While each item was originally answered with a seven-point Likert scale, the scale was converted to a five-point Likert scale in Turkish version. ${ }^{20}$

Multidimensional Scale of Perceived Social Support (MSPSS): This is a simple, easy-to-use 12 -item scale developed by Zimet et al. ${ }^{21}$ to screen perceived social support. The reliability and validity of the Turkish form are present. ${ }^{22}$ The items tended to divide into factor groups relating to the source of social support -namely; family, friends or significant other. The high score on the scale indicates high-perceived social support. $^{21}$

Visual analog scale (VAS): VAS was used to determine the severity of pain of patients. VAS is a $10-\mathrm{cm}$ line with left side representing no pain and right side representing intolerable pain. Patients were asked to mark the severity of pain they felt due to FMS on this line. Then, the distance of the marking to the starting point was measured with a ruler and recorded. ${ }^{23}$

\section{Statistical analysis}

Data obtained in this study were analyzed using the Statistical Program for Social Sciences version 16.0 (SPSS Inc., Chicago, IL, USA). Normally distributed data were expressed in mean and standard deviation, while abnormally distributed data were expressed in median (min-max). The chi-square test was used to compare the categorical data. For continuous data with normal distribution, one-way analysis of variance (ANOVA) was used to compare two groups. In comparison between the groups, the parametric ANOVA test was used because the data had Student's t-test requirements. The relationship between continuous variables with non-normal distribution was examined by the Spearman correlation analysis. A $p$ value of $<0.05$ was considered statistically significant for all analyses.

\section{RESULTS}

Sixty-five female patients with FMS and 52 healthy females were included in this study. The mean ages of the groups were $33.5 \pm 8.1$ years for FMS patients and 33.6 \pm 7.3 years for healthy controls $(\mathrm{F}=0.123 ; \mathrm{df}=115 ; \mathrm{p}=0.726)$. The presence of reported additional physical illness was significantly higher in FMS group than healthy controls. Sociodemographic characteristics are presented in Table 1.

The proportion of patients diagnosed with any mood or anxiety disorder using SCID-I was significantly different among FMS 


\begin{tabular}{|c|c|c|c|c|c|}
\hline & \multicolumn{2}{|c|}{ FMS patients } & \multicolumn{2}{|c|}{ Healthy controls } & \multirow[b]{2}{*}{$p$} \\
\hline & $\mathrm{n}$ & $\%$ & $\mathrm{n}$ & $\%$ & \\
\hline $\begin{array}{l}\text { Marital status } \\
\text { Married } \\
\text { Single }\end{array}$ & $\begin{array}{l}51 \\
14\end{array}$ & $\begin{array}{l}78.5 \\
21.5\end{array}$ & $\begin{array}{c}43 \\
9\end{array}$ & $\begin{array}{l}82.7 \\
17.3\end{array}$ & 0.74 \\
\hline $\begin{array}{l}\text { Educational status } \\
\text { Elemantary school } \\
\text { Secondary school or High school } \\
\text { College }\end{array}$ & $\begin{array}{l}25 \\
30 \\
10\end{array}$ & $\begin{array}{l}38.5 \\
46.15 \\
15.85\end{array}$ & $\begin{array}{c}21 \\
24 \\
7\end{array}$ & $\begin{array}{l}40.34 \\
46.15 \\
13.46\end{array}$ & 0.99 \\
\hline $\begin{array}{l}\text { Place of residence } \\
\text { City } \\
\text { Village }\end{array}$ & $\begin{array}{l}41 \\
24\end{array}$ & $\begin{array}{l}63.08 \\
36.92\end{array}$ & $\begin{array}{l}35 \\
17\end{array}$ & $\begin{array}{l}67.3 \\
32.7\end{array}$ & 0.78 \\
\hline $\begin{array}{l}\text { Working status } \\
\text { Yes }\end{array}$ & 14 & 21.5 & 17 & 32.7 & 0.25 \\
\hline $\begin{array}{c}\text { Smoking } \\
\text { Yes }\end{array}$ & 24 & 36.9 & 17 & 32.7 & 0.78 \\
\hline $\begin{array}{l}\text { Accompanying medical disorder } \\
\text { Yes }\end{array}$ & 23 & 35.4 & 8 & 15.4 & $0.026^{*}$ \\
\hline $\begin{array}{l}\text { Psychiatric history } \\
\text { Yes }\end{array}$ & 14 & 21.5 & 8 & 15.4 & 0.54 \\
\hline
\end{tabular}

( $\mathrm{n}=50,76.92 \%)$ and healthy control $(\mathrm{n}=14,33.33 \%)$ groups $(\mathrm{p}<0.001)$. Besides, the distribution of mood and anxiety disorder comorbidity in the FMS group also revealed a significant difference than that of the others, as shown in Table 2 $(p<0.001)$. Only 15 patients $(23.1 \%)$ with FMS were not diagnosed with any psychiatric disorders. The most common psychiatric diagnosis in the FMS group was anxiety disorder, not otherwise specified ( $n=13,20 \%)$.

The median HDRS scores were $19.1 \pm 10.2$ (7.00-43.00) (moderate depression) in FMS group and 9.6 \pm 6.6 (3.00-32.00) (no depression) in healthy controls. Depression levels were significantly different among two groups $(p<0.001)$. Post-hoc pairwise comparisons revealed that depression levels of FMS patients was significantly higher than those of healthy controls $(p<0.001)$. Also, nine patients with FMS had major depressive disorder while only three healthy controls had major depressive disorder. The median HARS scores were reported as $26.0 \pm 10.9$ (7.00-45.00) (major anxiety) in FMS group and 11.7 \pm 9.1 (3.00-41.00) (no anxiety) in healthy controls.

Table 2. Distribution of mood and anxiety disorders' frequency according to structured clinical interview for diagnostic and statistical manual of mental disorders fourth edition axis I disorders

\begin{tabular}{|c|c|c|c|c|c|}
\hline & \multicolumn{2}{|c|}{ FMS patients } & \multicolumn{2}{|c|}{ Healthy controls } & \multirow[b]{2}{*}{$p$} \\
\hline & $\mathrm{n}$ & $\%$ & $\mathrm{n}$ & $\%$ & \\
\hline No diagnosis & 15 & 23.08 & 38 & 73.08 & \multirow{8}{*}{$<0.001$} \\
\hline Generalized anxiety disorder & 6 & 9.2 & 1 & 1.92 & \\
\hline Major depresssive disorder & 9 & 13.85 & 3 & 5.77 & \\
\hline Adjustment disorder & 11 & 16.9 & 2 & 3.85 & \\
\hline Anxiety disorder not otherwise specified & 13 & 20 & 5 & 9.6 & \\
\hline Obsessive compulsive disorder & 6 & 9.2 & 1 & 1.92 & \\
\hline Panic disorder & 4 & 6.15 & 2 & 3.85 & \\
\hline Post-traumatic stress disorder & 1 & 1.5 & 0 & 0 & \\
\hline
\end{tabular}


Table 3. Mean scores of scales

\begin{tabular}{|c|c|c|c|c|c|c|c|}
\hline & \multicolumn{3}{|c|}{ Fibromyalgia syndrome } & \multicolumn{3}{|c|}{ Healthy control } & \multirow[b]{2}{*}{$p^{*}$} \\
\hline & Mean \pm SD & Median & Min-Max & Mean \pm SD & Median & Min-Max & \\
\hline Hamilton Anxiety Rating Scale & $26.0 \pm 10.9$ & 25 & $7-45$ & $11.7 \pm 9.1$ & 7 & $3-41$ & $<0.001$ \\
\hline Hamilton Depression Rating Scale & $19.1 \pm 10.2$ & 16 & $7-43$ & $9.6 \pm 6.6$ & 7 & $3-32$ & $<0.001$ \\
\hline Maslach depersonalization & $10.6 \pm 4.9$ & 11 & $1-20$ & $8.2 \pm 5.0$ & 6 & $1-22$ & 0.01 \\
\hline Maslach emotional exhaustion & $23.4 \pm 8.0$ & 23 & $4-36$ & $11.4 \pm 6.0$ & 11 & $4-29$ & $<0.001$ \\
\hline Maslach personal accomplishment & $16.6 \pm 5.6$ & 17 & $3-27$ & $10.6 \pm 5.5$ & 9.5 & $3-23$ & $<0.001$ \\
\hline MSPSS family & $12.7 \pm 4.4$ & 13 & $4-20$ & $14.9 \pm 4.8$ & 16 & $4-20$ & 0.01 \\
\hline MSPSS friends & $9.7 \pm 4.8$ & 8 & $4-20$ & $13.8 \pm 4.1$ & 15 & $4-20$ & $<0.001$ \\
\hline MSPSS significant other & $11.2 \pm 5.0$ & 10 & $4-20$ & $14.7 \pm 4.2$ & 15 & $5-20$ & $<0.001$ \\
\hline MSPSS total score & $33.6 \pm 13.2$ & 30 & $12-60$ & $43.4 \pm 11.6$ & 45.5 & $15-60$ & $<0.001$ \\
\hline Visual analog scale & $7.42 \pm 1.91$ & 8 & $3-10$ & & & & \\
\hline
\end{tabular}

Anxiety levels were significantly different among two groups $(\mathrm{p}<0.001)$.

The median MSPSS family subscale scores were reported as $12.7 \pm 4.4(4-20)$ in FMS group and 14.9 $\pm 4.8(4-20)$ in healthy controls. MSPSS family subscale score was significantly lower in FMS group $(p<0.001)$. The median MSPSS friends subscale scores were reported as $9.7 \pm 4.8$ (4-20) in FMS group and 13.8 \pm 4.1 (4-20) in healthy controls. MSPSS friends subscale score was significantly lower in FMS group $(p<0.001)$. The median MSPSS significant other subscale scores were reported as 11.2 \pm 5.0 (4-20) in FMS group and $14.7 \pm 4.2(5-20)$ in healthy controls. MSPSS significant other subscale score was significantly lower in FMS group $(\mathrm{p}<0.001)$. The median MSPSS total scores were reported as $33.6 \pm 13.2(12-60)$ in FMS group and $43.4 \pm 11.6$
(15-60) in healthy controls. MSPSS total score was significantly lower in FMS group ( $p<0.001)$.

The median MBI emotional exhaustion subscale scores were reported as 23.4 \pm 8.0 (4-36) in FMS group and 11.4 \pm 6.0 (4-29) in healthy controls. MBI emotional exhaustion subscale score was significantly higher in FMS group $(p<0.001)$. The median MBI depersonalization subscale scores were reported as 10.6 \pm 4.9 (1-20) in FMS group and 8.2 $\pm 5.0(1-22)$ in healthy controls. MBI depersonalization subscale score was significantly higher in FMS group $(\mathrm{p}<0.001)$. The median MBI personal accomplishment subscale scores were reported as 16.6 \pm 5.6 (3-27) in FMS group and $10.6 \pm 5.5$ (3-23) in healthy controls. MBI personal accomplishment subscale score was significantly higher in FMS group $(\mathrm{p}<0.001)$. The median VAS score was 7.42 \pm 1.91 (3-10). Detailed data

Table 4. Correlation between scales in fibromyalgia syndrome group

\begin{tabular}{lccccccc}
\hline & HDRS & HARS & VAS & MSPSS & EE & D & PA \\
\hline Hamilton Depression Rating Scale & 1 & $0.503^{*}$ & $0.537^{*}$ & $-0.32^{*}$ & $0.573^{*}$ & $0.401^{*}$ & $0.432^{*}$ \\
Hamilton Anxiety Rating Scale & $0.503^{*}$ & 1 & $0.672^{*}$ & $-0.67^{*}$ & $0.644^{*}$ & $0.624^{*}$ & $0.641^{*}$ \\
Visual analog scale & $0.537^{*}$ & $0.672^{*}$ & 1 & $-0.447^{*}$ & $0.591^{*}$ & $0.543^{*}$ & $0.53^{*}$ \\
Multidimensional Scale of Perceived Social & $-0.32^{*}$ & $-0.67^{*}$ & $-0.447^{*}$ & 1 & $-0.604^{*}$ & $-0.599^{*}$ & $-0.685^{*}$ \\
Support & & & & & & & \\
Emotional exhaustion & $0.573^{*}$ & $0.644^{*}$ & $0.591^{*}$ & $-0.604^{*}$ & 1 & $0.729^{*}$ & $0.752^{*}$ \\
Depersonalization & $0.401^{*}$ & $0.624^{*}$ & $0.543^{*}$ & $-0.599^{*}$ & $0.729^{*}$ & 1 & $0.773^{*}$ \\
Personal accomplishment & $0.432^{*}$ & $0.641^{*}$ & $0.53^{*}$ & $-0.685^{*}$ & $0.752^{*}$ & $0.773^{*}$ & 1 \\
\hline
\end{tabular}

HDRS: Hamilton Depression Rating Scale; HARS: Hamilton Anxiety Rating Scale; VAS: Visual analog scale; MSPSS: Multidimensional Scale of Perceived Social Support; EE: Emotional exhaustion; D: Depersonalization; PA: Personal accomplishment; * Spearman's correlation test. Correlation was significant at $\mathrm{p}<0.01$. 
on mean scores of the scales are presented in Table 3.

Correlations between these variables were examined within the FMS group. There was a significant negative correlation between VAS and MSPSS. There were significant negative correlations between MSPSS and HDRS, HARS, all subscales of MBI. There were significant positive correlations between VAS and HDRS, HARS, all subscales of MBI. There were positive significant correlations between $\mathrm{MBI}$ emotional exhaustion, depersonalization and personal accomplishment subscales and HDRS, HARS and VAS. The correlation between the scales in FMS group is presented in Table 4.

\section{DISCUSSION}

The purpose of this study was to assess the impact of perceived social support on severity of pain, burnout and comorbid depression and anxiety among Turkish females with FMS. Nevertheless, much of the research on FMS has focused on examining its etiological causes, prevalence, accompanying psychiatric disorders and temperament profiles of patients by using some relevant questionnaires. In this study, we assessed patients with FMS not only through questionnaires but also using a semi-structured psychiatric interview.

Psychiatric profiles of the groups were significantly different from each other. This finding is consistent with the results of studies performed by using SCID in the literature. ${ }^{24,25}$ There are many studies in the literature conducted on FMS and comorbid psychiatric disorders. Epstein et al. ${ }^{25}$ found that patients with FMS showed high levels of lifetime and current psychiatric disorders. Also, patients with FMS are at significant risk for depression and anxiety disorders and related psychiatric conditions. ${ }^{24}$

Pain experienced by patients with FMS is often obscure or contradictory and can sometimes be localized or widespread and variable. ${ }^{26}$ Pain related with FMS not only has a physical but also a mental component. Also, it is assumed that this pain is one of the causes for the severity of other common comorbid FMS symptoms such as fatigue, sleep disturbances, anxiety and depression. ${ }^{27}$
Depression associated with pain can contribute to sadness, low self-esteem and decreases in the belief that pain can be managed or controlled. Depression can also contribute to the experience of pain itself, given evidence that people with depression have greater sensitivity to pain. ${ }^{28}$ Indeed, it appears that significantly greater proportion of people with depression, compared to people without depression, suffer from chronic pain. ${ }^{29}$ Pain and depression frequently coexist because of sharing common pathophysiological processes. ${ }^{30}$ Depression is also associated with impairment of the functions of pain modulating structures. ${ }^{31}$ It is thought that depression may be associated with decreased pain threshold. Common physiopathogenetic factors are also observed at neurotransmitter levels in FMS and depressed patients. ${ }^{32}$

Also, the literature reveals important relationships between anxiety and severity of pain. The possible mechanisms are explained as follows: first, pain might lead to feelings of anxiety. Second, anxiety itself can make individuals more sensitive to pain and its unfavorable impacts. Third, anxiety, whether associated with fear or not, contributes to hypervigilance and avoidance behaviors by ensuring that the pain experience persists. ${ }^{33,34}$ The pain perception can subscribe to expectations that an event or behavior may cause or increase the pain. This can cause to amplify both fear and anxiety and can result in hypervigilance to bodily sensations and avoidance behaviors, followed by disability, anxiety and depression, and finally to preservation and aggravations of pain. ${ }^{34}$ Decreased daily activities due to avoidance behavior related with pain can result in social isolation, decreased self-esteem, increased feelings of insufficiency, and increased anxiety and depression. ${ }^{35}$

Social support seems to be a good coping resource for patients having chronic illnesses. Relevant literature revealed the positive impacts of social support on health and well-being for patients. Positively perceived social support improves recovery from illness. Patients who perceive appropriate support from their family, friends or partners are more likely to have reduced stress and find useful ways to recover from illness. ${ }^{36,37}$

There are two main factors that make FMS a stigmatized illness: the diagnosis process of 
this invisible illness and the nature of the illness with the intangible etiology. ${ }^{38}$ Because FMS does not have any visible external signs or abnormal tests, social supporters of patients may regard the patient as simulating an illness. This may increase the stigmatization potential of patients. The stigmatization may also reduce receiving and perceiving the social support. ${ }^{39,40}$ Chronic pain and comorbid psychiatric disorders associated with FMS affect patients' ability to establish and maintain emotional and physical contact with those around them. This may lead to developing strategies to cope with chronic pain and other comorbid symptoms associated with FMS and eventually to exhaustion in the patient. In a study on the experiences of African-American females with FMS, one striking result was that individuals kept their experience with this invisible illness a secret from their families and friends. Due to others' reactions, misunderstandings, or a fear of burdening others, these females limited sharing their illness. ${ }^{40}$ Other research among patients living with FMS has found that family support was extremely important as a coping resource with the illness. Furthermore, this study revealed that patients preferred not to share their experiences with their family as a result of decreased perceived family support and increased stigmatization. ${ }^{41}$

Stress and coping strategies with FMS affect how individuals perceive social support. For females with FMS in our study, decreased perceived social support was associated with increased severity of pain, depression and anxiety symptoms. In a study conducted by Cano et al., ${ }^{42}$ it was suggested that negative responses from spouses to their pain for individuals with chronic pain were associated with increased severity of pain and decreased marital satisfaction, which may lead to increased depressive symptoms. In addition to its invisible nature and difficulty of diagnosis, another cause of stigma and having higher levels of stress for patients with FMS is comorbid psychiatric disorders like depression, anxiety and post-traumatic stress disorder. ${ }^{4}$ Nevertheless, these comorbid psychiatric disorders are invisible illnesses too.

Patients with FMS have difficulty in planning social activities with their family, partners or friends because they have difficulty to predict how they would feel. ${ }^{43}$ This may lead to increased social isolation, decreased perception of social support, and consequently an increased severity of depression, anxiety and burnout. Limitations in daily life activities and comorbid psychiatric disorders, particularly depression and anxiety, and not positively perceived social support impose an important burnout among patients with FMS. ${ }^{43}$

Examining the relevant literature, we have found only limited research that reveals the relationships between use of social support groups and dealing with FMS.9,40,44 Thus, we hope that our study will help clinicians to understand the important role of perceived social support in reducing the illness related chronic pain, anxiety, depression and burnout in FMS. Some studies have suggested that social support has positive impact on coping with chronic pain disorders like FMS. ${ }^{9,45,46,47}$ Studies have also revealed that social support has positive effects on comorbid psychiatric disorders and severity of pain. ${ }^{45,48}$ Franks et al. ${ }^{13}$ revealed that when assessing depression, helplessness, mood disturbance, quality of well-being, and impact of FMS, being satisfied with one's social support appears to be important for females with FMS. In a study conducted among Brazilian females with FMS, it was revealed that positive social support was negatively associated with impacts of FMS and depression. This study emphasizes that social support appears to contribute to improve both mental and physical health in patients with FMS and the perception of poor social support may be influenced by severity of symptoms. $^{9}$

In our study, we also evaluated the correlations between severity of pain, anxiety, depression, burnout and all subscales of MSPSS. MSPSS family, friends and significant others subscale scores were significantly lower in FMS group and MSPSS all subscales were found to be negatively correlated with anxiety, depression and burnout. This finding is consistent with the results of other studies. ${ }^{40,47,49}$ In a study conducted to examine the associations between perceived social support and severity of depression and anxiety among females with FMS, it was revealed that females with FMS reported less perceived family support and lower mood than healthy controls and there was a significant association with higher rates of anxiety and depression. ${ }^{47} \mathrm{~A}$ study conducted by Montoya et al. ${ }^{49}$ demonstrated significant reductions in sensitivity of pain and subjective 
pain ratings in the presence of social support through the patient's significant other.

There are some limitations of our study. The FMS patients in our study did not constitute a homogeneous group, instead contained both newly diagnosed and treatment resistant patients. In this study, we were unable to examine the relationship between treatment resistance and perceived social support due to the heterogeneity in the sample group. Furthermore, our study was performed with a patient group seeking for treatment. Therefore, our results cannot be generalized to the general population. Individuals seeking treatment are more likely to report pain symptoms than those who do not. Finally, it should also be remembered that our study was only performed in the female patient group.

In conclusion, perceived social support was found to be strongly associated with depression, anxiety, burnout and severity of pain in patients with FMS in this case control study. Our study provided support to emphasize the importance of perceived social support among females with FMS. People having invisible illnesses such as FMS rarely share the details of their illness and do not receive high levels of social support. ${ }^{50}$ Patients feel stigmatized because of invisible symptoms such as not only chronic pain but also comorbid depression and anxiety. Thus, they cannot receive the required social support. ${ }^{43}$ Since FMS does not cause visible symptoms and disabilities and FMS itself does not have specific laboratory and radiological data, females with FMS usually face with suspicion from their families, employers, friends and clinicians. This may lead to decreased perceived social support due to stigmatization and increased burnout due to facing physical and emotional distress. ${ }^{9,10}$ We hope that our findings play an important role in developing multidisciplinary treatment approaches based on comprehensive biopsychosocial models addressing the variety of psychiatric symptoms and burnout associated with FMS. Our findings suggest important interrelations among biological, psychological, and social support systems that impact FMS. As a result, multidisciplinary treatment approaches should include questioning the perceived social support.

\section{Declaration of conflicting interests}

The authors declared no conflicts of interest with respect to the authorship and/or publication of this article.

\section{Funding}

The authors received no financial support for the research and/or authorship of this article.

\section{REFERENCES}

1. Wolfe F, Clauw DJ, Fitzcharles MA, Goldenberg DL, Katz RS, Mease P, et al. The American College of Rheumatology preliminary diagnostic criteria for fibromyalgia and measurement of symptom severity. Arthritis Care Res (Hoboken) 2010;62:600-10.

2. Lawrence RC, Felson DT, Helmick CG, Arnold LM, Choi H, Deyo RA, et al. Estimates of the prevalence of arthritis and other rheumatic conditions in the United States. Part II. Arthritis Rheum 2008;58:26-35.

3. Topbas M, Cakirbay H, Gulec H, Akgol E, Ak I, Can G. The prevalence of fibromyalgia in women aged 20-64 in Turkey. Scand J Rheumatol 2005;34:140-4.

4. González E, Elorza J, Failde I. Fibromyalgia and psychiatric comorbidity: their effect on the quality of life patients. Actas Esp Psiquiatr. 2010;38:295-300.

5. Mease P, Arnold LM, Bennett R, Boonen A, Buskila D, Carville S, et al. Fibromyalgia syndrome. J Rheumatol 2007;34:1415-25.

6. Kempner J. Invisible people with invisible pain: A commentary on "Even my sister says I'm acting like a crazy to get a check": Race, gender, and moral boundary-work in women's claims of disabling chronic pain. Soc Sci Med 2017;189:152-4.

7. Dysvik E, Natvig GK, Eikeland OJ, Lindstrøm TC. Coping with chronic pain. Int $J$ Nurs Stud 2005;42:297-305.

8. Van Damme S, Crombez G, Eccleston C. Coping with pain: a motivational perspective. Pain 2008;139:1-4.

9. Freitas RPA, Andrade SC, Spyrides MHC, Micussi MTABC, Sousa MBC. Impacts of social support on symptoms in Brazilian women with fibromyalgia. Rev Bras Reumatol Engl Ed 2017;57:197-203.

10. Phillips LJ, Stuifbergen AK. The relevance of depressive symptoms and social support to disability in women with multiple sclerosis or fibromyalgia. Int $J$ Rehabil Res 2010;33:142-50.

11. Dambi JM, Corten L, Chiwaridzo M, Jack H, Mlambo T, Jelsma J. A systematic review of the psychometric properties of the cross-cultural translations and adaptations of the Multidimensional Perceived Social Support Scale (MSPSS). Health Qual Life Outcomes 2018;16:80.

12. Thoits PA. Mechanisms linking social ties and support to physical and mental health. $J$ Health Soc Behav 2011;52:145-61. 
13. Franks HM, Cronan T, Oliver K. Social support in women with fibromyalgia: Is quality more important than quantity? J Community Psychol 2004;32:425-38.

14. Spitzer RL, Williams JB, Gibbon M, First MB. The Structured Clinical Interview for DSM-IV Axis I Disorders, Clinician Version (SCID-CV). Washington, D.C.: American Psychiatric Press Inc; 1996.

15. Williams JB. A structured interview guide for the Hamilton Depression Rating Scale. Arch Gen Psychiatry 1988;45:742-7.

16. Akdemir A, Örsel S, Dağ İ, Türkçapar H, İşcan $\mathrm{N}$, Özbay $\mathrm{H}$. Hamilton depresyon derecelendirme ölçeği (HDDO)'nin geçerliliği-güvenilirliği ve klinikte kullanımı. Psikiyatri Psikoloji Psikofarmakoloji Dergisi 1996;4:251-9.

17. Hamilton M. The assessment of anxiety states by rating. Br J Med Psychol 1959;32:50-5.

18. Yazıcı MK, Demir B, Tanrıverdi N, Karaağaoğlu E, Yolaç P. Hamilton Anksiyete Değerlendirme Ölçeği, değerlendiriciler arası güvenirlik ve geçerlik çalışması Türk Psikiyatri Dergisi 1998;9:114-7.

19. Maslach C, Jackson SE. The measurement of experienced burnout. Journal of Organizational Behavior 1981;2:99-113.

20. Ergin C. Doktor ve hemşirelerde tükenmişlik ve Maslach tükenmişlik ölçeğinin uyarlanması. VII. Ulusal Psikoloji Kongresi Bilimsel Çalışmaları, Ankara: Türk Psikologlar Derneği Yayınları; 1992. s. 143-54.

21. Zimet GD, Dahlem NW, Zimet SG. The multidimensional scale of perceived social support. J Pers Assess 1988;52:30-41.

22. Eker D, Arkar H. Çok Boyutlu algılanan sosyal destek ölçeğinin faktör yapısı, geçerlilik ve güvenirliği. Türk Psikologlar Dergisi 1995;10:45-55.

23. McCormack HM, Horne DJ, Sheather S. Clinical applications of visual analogue scales: a critical review. Psychol Med 1988;18:1007-19.

24. Consoli G, Marazziti D, Ciapparelli A, Bazzichi L, Massimetti G, Giacomelli $\mathrm{C}$, et al. The impact of mood, anxiety, and sleep disorders on fibromyalgia. Compr Psychiatry 2012;53:962-7.

25. Epstein SA, Kay G, Clauw D, Heaton R, Klein D, Krupp L, et al. Psychiatric disorders in patients with fibromyalgia. A multicenter investigation. Psychosomatics 1999;40:57-63.

26. Söderberg S, Lundman B. Transitions experienced by women with fibromyalgia. Health Care Women Int 2001;22:617-31.

27. Paulson M, Danielson E, Söderberg S. Struggling for a tolerable existence: the meaning of men's lived experiences of living with pain of fibromyalgia type. Qual Health Res 2002;12:238-49.

28. Bär KJ, Brehm S, Boettger MK, Boettger S, Wagner G, Sauer H. Pain perception in major depression depends on pain modality. Pain 2005;117:97-103.

29. Arnow BA, Hunkeler EM, Blasey CM, Lee $\mathrm{J}$, Constantino $\mathrm{MJ}$, Fireman $\mathrm{B}$, et al. Comorbid depression, chronic pain, and disability in primary care. Psychosom Med 2006;68:262-8.

30. Maletic V, Raison CL. Neurobiology of depression, fibromyalgia and neuropathic pain. Front Biosci (Landmark Ed) 2009;14:5291-338.

31. Giesecke T, Gracely RH, Williams DA, Geisser ME, Petzke FW, Clauw DJ. The relationship between depression, clinical pain, and experimental pain in a chronic pain cohort. Arthritis Rheum 2005;52:1577-84

32. Kalia M. Neurobiological basis of depression: an update. Metabolism 2005;54:24-7.

33. Keefe FJ, Rumble ME, Scipio CD, Giordano LA, Perri LM. Psychological aspects of persistent pain: current state of the science. J Pain 2004;5:195-211.

34. Vlaeyen JW, Linton SJ. Fear-avoidance and its consequences in chronic musculoskeletal pain: a state of the art. Pain 2000;85:317-32.

35. McGuire B, Hogan M, Morrison T. Dimensionality and reliability assessment of the pain patient profile questionnaire. Eur J Psychol Assess 2008;24:22-6.

36. Cohen S. Social relationships and health. Am Psychol 2004;59:676-84.

37. Lett HS, Blumenthal JA, Babyak MA, Catellier DJ, Carney RM, Berkman LF, et al. Social support and prognosis in patients at increased psychosocial risk recovering from myocardial infarction. Health Psychol 2007;26:418-27.

38. Sturge-Jacobs M. The experience of living with fibromyalgia: confronting an invisible disability. Res Theory Nurs Pract 2002;16:19-31.

39. Asbring $P$, Närvänen AL. Women's experiences of stigma in relation to chronic fatigue syndrome and fibromyalgia. Qual Health Res 2002;12:148-60.

40. Schaefer KM. The lived experience of fibromyalgia in African American women. Holist Nurs Pract 2005; 19:17-25.

41. Wuytack F, Miller P. The lived experience of fibromyalgia in female patients, a phenomenological study. Chiropr Man Therap 2011;19:22.

42. Cano A, Weisberg JN, Gallagher RM. Marital satisfaction and pain severity mediate the association between negative spouse responses to pain and depressive symptoms in a chronic pain patient sample. Pain Med 2000;1:35-43.

43. Arnold LM, Crofford LJ, Mease PJ, Burgess SM, Palmer SC, Abetz L, et al. Patient perspectives on the impact of fibromyalgia. Patient Educ Couns 2008;73:114-20.

44. Kelley P, Clifford P. Coping with chronic pain: assessing narrative approaches. Soc Work 1997;42:266-77.

45. López-Martínez AE, Esteve-Zarazaga R, RamírezMaestre C. Perceived social support and coping responses are independent variables explaining pain adjustment among chronic pain patients. J Pain 2008;9:373-9.

46. Tsai PF, Tak S, Moore C, Palencia I. Testing a theory of chronic pain. J Adv Nurs 2003;43:158-69. 
47. Shuster J, McCormack J, Pillai Riddell R, Toplak ME. Understanding the psychosocial profile of women with fibromyalgia syndrome. Pain Res Manag 2009; 14:239-45.

48. Campbell LC, Clauw DJ, Keefe FJ. Persistent pain and depression: a biopsychosocial perspective. Biol Psychiatry 2003;54:399-409.

49. Montoya P, Larbig W, Braun C, Preissl H, Birbaumer N.
Influence of social support and emotional context on pain processing and magnetic brain responses in fibromyalgia. Arthritis Rheum 2004;50:4035-44.

50. Schoofs N, Bambini D, Ronning P, Bielak E, Woehl J. Death of a lifestyle: the effects of social support and healthcare support on the quality of life of persons with fibromyalgia and/or chronic fatigue syndrome. Orthop Nurs 2004;23:364-74. 